\title{
Cross-sectional analysis of sleep hours and quality with sex hormones in men
}

\author{
Morten Ruge', Tea Skaaby', Anna-Maria Andersson ${ }^{2,3}$ and Allan Linneberg 1,4,5 \\ ${ }^{1}$ Center for Clinical Research and Disease Prevention, Bispebjerg and Frederiksberg Hospital, The Capital Region, Copenhagen, Denmark \\ 2Department of Growth and Reproduction, Rigshospitalet, University of Copenhagen, Copenhagen, Denmark \\ ${ }_{3}^{3}$ International Center for Research and Research Training in Endocrine Disruption of Male Reproduction and Child Health (EDMaRC), Rigshospitalet, \\ University of Copenhagen, Copenhagen, Denmark \\ ${ }^{4}$ Department of Clinical Experimental Research, Rigshospitalet, Copenhagen, Denmark \\ ${ }^{5}$ Department of Clinical Medicine, Faculty of Health and Medical Sciences, University of Copenhagen, Copenhagen, Denmark
}

Correspondence should be addressed to A-M Andersson: Anna-Maria.Andersson@regionh.dk

\begin{abstract}
Background: Reduced total hours of sleep and low quality of sleep have been suggested to be associated with low levels of male hormones. Few studies have examined the association between excessive sleep and male reproductive hormones.

Objective: To investigate the association of total hours of sleep and quality of sleep with serum levels of total, bioavailable and free testosterone (tT, bT and fT), sex hormonebinding globulin (SHBG) and dehydroepiandrosteron-sulfate (DHEAS).

Methods: Serum levels of tT, SHBG and DHEAS were measured with immunoassays in a cross-sectional population-based study of 2095 males. bT and fT were calculated in accordance with Vermeulens method. Information on total hours of sleep and sleep quality was obtained by questionnaire. Linear regression was used to calculate hormones according to total hours of sleep and the results were expressed as $\beta$-estimates and $95 \%$ confidence intervals $(\mathrm{CI})$. The adjustment in the multivariable models was constructed taking age, BMI, smoking, alcohol intake and physical activity into account.

Results: Excessive sleep (>9 h) compared to 7-9 h of sleep was significantly associated with lower $\mathrm{tT}$, bT and fT, but not with SHBG or DHEAS, after multivariable adjustment. These significant associations were also found in our analyses with hormones as continuous variables but no associations were found in our general additive model analyses.

Conclusions: In this cross-sectional study in men, excessive sleep associated with lower levels of male reproductive hormones. Longitudinal studies are needed to determine the causal direction of the observed association between excessive sleep and lower male reproductive hormones levels.
\end{abstract}

\author{
Key Words \\ - testosterone \\ - SHBG \\ - DHEAS \\ - sleep \\ - hypogonadism
}

\section{Introduction}

Male hypogonadism is a condition in which the body produces little or no testosterone, and the risk is increased in the middle- and older-aged male population (1). The primary symptoms are reduced libido, lack of effect of phosphodiesterase type 5 (PDE5) inhibitors for erectile dysfunction, reduced muscle mass and strength, depressed mood, decreased energy and low bone mass (2). As the mean age of the populations in the Western world is rising, the prevalence of this condition is likely to rise with it (3).
Endocrine Connections (2019) 8, 141-149 
The need for sleep changes as humans grow older. It is recommended that newborns sleep $14-17 \mathrm{~h}$ per day, but as humans reach the age of 18 years, the need for sleep stabilizes at 7-9h of sleep per night (4). Insomnia is prevalent in a number of diseases, but it is also an independent disorder (5). It is most often defined by patients having difficulty falling or staying asleep, despite having optimal circumstances to sleep, and this sleep restriction had a negative impact on their daily life $(5,6)$. An American review found that between 28 and $40 \%$ of the general population sleeps less than $7 \mathrm{~h}$ (7). Insufficient sleep is associated with diabetes and cardiovascular disease (7), as well as impairment of both physical and cognitive function, psychiatric disorders like depression and a negative influence on emotional and social factors (6). Hypersomnia, on the other hand, is characterized by an increased amount of sleep, excessive daytime sleep or sleepiness. Narcolepsy, medication-dependent sleepiness, and hypersomnia associated with endocrine disorders are just a few of the broad spectrum of disorders and diseases covered by the term hypersomnia. It has the obvious risks of getting the affected involved in accidents at work, or while driving, as well as having a major negative impact on social and family life (8), and studies have also found an inverted u-shaped association between sleep and mortality, that is, both insufficient and excessive sleep are associated with increased mortality $(9,10,11)$.

In healthy men, the testosterone concentration peaks in the morning and falls during the day. It is restored to its peak after approximately $90 \mathrm{~min}$ of sleep, coinciding with the first REM phase of sleep (3). This diurnal pattern is likely to be directly dependent on sleep (12) rather than circadian rhythm and the light-darkness cycle that are known to affect melatonin and cortisol levels. Instead, sleep stimulates the synthesis of gonadotropin-releasing hormone (GnRH) from the hypothalamus, which binds to the gonadotrophs of the anterior pituitary and stimulates the release of luteinizing hormone (LH) and folliclestimulating hormone (FSH). FSH and $\mathrm{LH}$ travel through the bloodstream to the testes, where FSH stimulates the spermatogenesis, and $\mathrm{LH}$ stimulates testosterone production and secretion in the Leydig cells.

The associations between male reproductive hormones and sleep have previously been studied, but results have been inconclusive. Less healthy sleep and low serum levels of testosterone in males were found to be associated in one study (13), but these results could not be replicated by other studies $(14,15,16)$. Likewise, two studies found an association between insufficient sleep and low levels of male reproductive hormones in men $(17,18)$, but another study found no correlation (19). To our knowledge, no studies have found an association between excessive sleep and hormone levels $(13,15,17,18,19)$.

We hypothesized that an increased number of hours of sleep per night would lead to higher concentrations of serum testosterone, and thus, the present study sought to evaluate associations of sex hormone-binding globulin (SHBG), dihydroepiandrosteron-sulfate (DHEAS), total testosterone (tT), free testosterone (fT) and bioavailable testosterone (bT) with self-reported tiredness/fatigue and sleeplessness as well as self-reported total hours of sleep per day in 2095 males from a population-based sample.

\section{Methods}

\section{Study population}

We included men participating in the 5-year follow-up of the Inter99 study. The characteristics of the participants and the design of the study have been described in more detail elsewhere (20). In short, the Inter99 study was carried out from 1999 to 2001 and included 6784 participants drawn from an age- and sex-stratified random sample of the population. From 2004 to 2006 a 5-year-follow-up was conducted with 4513 individuals participating, of which 2255 were men. The health examination included a self-administered questionnaire, a physical examination and blood sampling. The questionnaire provided information on age, smoking habits, alcohol consumption, physical activity, sleep quality and total hours of sleep per night and the physical examination measured weight and height. The precise time of the day of blood sampling was not registered, but all blood samples were taken between 08:00 and 13:00 $\mathrm{h}$ and participants were fasting. The Inter99 study was registered in the ClinicalTrials.gov (NCT00289237), approved by the Ethics Committee of Copenhagen County (KA98155), and informed consent was obtained from all participants of the study.

Of the 2255 men participating in the 5-year follow-up of the Inter99 study, 51 participants were excluded $(n=2204)$ due to missing data on hormone concentrations, 99 participants were excluded $(n=2105)$ due to incomplete questionnaire data, and ten participants were excluded $(n=2095)$ because they reported less than $1 \mathrm{~h}$ of sleep per night, which we considered to be unlikely. Thus, we ended up with a total of 2095 men.
This work is licensed under a Creative Commons Attribution-NonCommercial 4.0 International License. ded from Bioscientifica.com at 04/26/2023 01:16:54PM 


\section{Hormone measurements}

Serum total testosterone and SHBG were measured by time-resolved fluoroimmunoassay and time-resolved immunofluorometric assay (DELFIA; Wallac OY, Turku, Finland), respectively, and expressed in nmol/L. DHEAS was measured by chemiluminescent immunoassay (Immulite 2000XPi, Siemens Healthcare Diagnostics) and expressed in $\mathrm{mg} / \mathrm{L}$. Serum levels of albumin were measured by Bromkresolpurpur (BCP)-Adaptation (Dimension VISTA, Siemens Healthcare Diagnostics) and expressed in $\mathrm{g} / \mathrm{L}$.

The coefficients of variation (CVs) for measurements of testosterone were 13.3 and $10.7 \%$ at low and high concentrations, respectively. The CVs for SHBG were 6.4 and $8.5 \%$ at low and high concentrations, respectively. The CVs for DHEAS were 7.9 and $7.1 \%$ at low and high concentrations, respectively.

The levels of free and bioavailable testosterone were calculated by using the measured concentrations of albumin, SHBG and total testosterone in accordance with the method presented by Vermeulen (21).

The three measured hormone concentrations, tT, SHBG and DHEAS, and the two calculated additional measures of testosterone, fT, and bT, were used as the five primary outcomes of the present study.

\section{Lifestyle factors}

Participants were divided into three age categories (35-45, 45-55 and 55-60 years of age). BMI was calculated as weight $(\mathrm{kg})$ divided by height $(\mathrm{m})$ squared and divided into four groups $\left(<18.5,18.5-25,25-30\right.$ and $\left.>30 \mathrm{~kg} / \mathrm{m}^{2}\right)$ (22). Three participants had a BMI below 18.5 and were excluded when presenting BMI as a classified variable in Table 1, as well as Supplementary Tables 1 and 2 (see section on supplementary data given at the end of this article). In the multivariable linear regression presented in Table 2, and Supplementary Table 3, BMI was used as a continuous variable, and the three participants were included.

The participants were categorized in four different classes according to their self-reported smoking habits: current smokers, former smokers, occasional smokers and never smokers. Participants who answered confirmatory to the question 'No, I quit since the start of Inter99 (baseline)' or 'No, but I am a former smoker' were classified as former smokers. According to self-reported alcohol intake, the mean amount of units of alcohol per week was calculated and classified as $0,1-14$ and $>14$ units per week, according to the recommendations from The Danish Health Authority (https://www.sst.dk/en/healthand-lifestyle/alcohol accessed 3/12/17). Participants were classified as 'mainly sedentary', 'light-to-moderate activity', 'regular sport', or 'exercise or athletic training' according to their self-reported physical activity.

To assess co-morbidities, we used data on self-reported asthma, myocardial infarction, diabetes, heart medication

Table 1 Characteristics of the population $(n=2095)$ and associations of total testosterone with relevant cofounders.

\begin{tabular}{|c|c|c|}
\hline & $\%(n)$ & $\begin{array}{c}\text { Total testo (pmol/L) } \\
\text { Median (IQR) } \\
\end{array}$ \\
\hline \multicolumn{3}{|l|}{ Often sleepless } \\
\hline Yes & $11.8(248)$ & $13.3(9.9 ; 17.1)$ \\
\hline No & $88.2(1847)$ & $\begin{array}{c}14.4(11.4 ; 18.4) \\
P<0.001\end{array}$ \\
\hline \multicolumn{3}{|l|}{ Often very tired } \\
\hline Yes & $15.8(331)$ & $14.1(10.9 ; 18.4)$ \\
\hline No & $84.2(1764)$ & $\begin{array}{c}14.4(11.3 ; 18.1) \\
P=0.547\end{array}$ \\
\hline \multicolumn{3}{|l|}{$\begin{array}{l}\text { Self-reported total hours } \\
\text { of sleep }\end{array}$} \\
\hline$<7 \mathrm{~h}$ of sleep & $23.4(491)$ & $14.7(11.8 ; 18.8)$ \\
\hline 7-9 h of sleep & $72.4(1518)$ & $14.2(11.1 ; 18.1)$ \\
\hline$>9 \mathrm{~h}$ of sleep & $4.1(86)$ & $\begin{array}{c}12.7(8.9 ; 16.2) \\
P=0.002\end{array}$ \\
\hline \multicolumn{3}{|l|}{ Age } \\
\hline $35-45$ & $11.7(244)$ & $14.9(12.2 ; 19.7)$ \\
\hline $45-55$ & $62.7(1313)$ & $14.5(11.3 ; 18.4)$ \\
\hline $55-60$ & $25.7(538)$ & $\begin{array}{c}13.6(10.4 ; 17.2) \\
P<0.001\end{array}$ \\
\hline \multicolumn{3}{|l|}{$\mathrm{BMI}$} \\
\hline Underweight (<18.5 kg/m²) & $0.1(3)$ & $21.3(15.4 ; 22.2)$ \\
\hline Normal $(18.5-25$ kg/m²) & $31.2(654)$ & $16.3(12.8 ; 20.8)$ \\
\hline Overweight $\left(25-30 \mathrm{~kg} / \mathrm{m}^{2}\right)$ & $49.9(1046)$ & $14.2(11.4 ; 17.7)$ \\
\hline Obese $\left(>30 \mathrm{~kg} / \mathrm{m}^{2}\right)$ & $18.7(392)$ & $\begin{array}{c}11.7(8.8 ; 14.7) \\
P<0.001\end{array}$ \\
\hline \multicolumn{3}{|l|}{ Smoking status } \\
\hline Daily smoker & $21.8(456)$ & $16.5(12.9 ; 20.7)$ \\
\hline Occasional smoker & $3.5(73)$ & $13.1(10.6 ; 15.6)$ \\
\hline Former smoker & $35.8(750)$ & $13.5(10.5 ; 17.1)$ \\
\hline Never smoker & $39.0(816)$ & $\begin{array}{c}14.1(11.2 ; 17.7) \\
P<0.001\end{array}$ \\
\hline \multicolumn{3}{|l|}{$\begin{array}{l}\text { Alcohol intake (units } \\
\text { per week) }\end{array}$} \\
\hline 0 units of alcohol & $5.9(123)$ & $14.4(11.0 ; 18.9)$ \\
\hline $1-14$ units of alcohol & $57.7(1208)$ & $14.3(11.2 ; 17.9)$ \\
\hline$>14$ units of alcohol & $36.5(764)$ & $\begin{array}{c}14.2(11.2 ; 18.5) \\
P=0.880\end{array}$ \\
\hline \multicolumn{3}{|l|}{ Physical activity } \\
\hline Mainly sedentary & $15.5(325)$ & $13.5(10.2 ; 17.6)$ \\
\hline Light to moderate activity & $60.1(1277)$ & $14.1(11.1 ; 18.1)$ \\
\hline Regular sport and excercise & $21.9(458)$ & $15.1(12.2 ; 18.6)$ \\
\hline Athletic training & $1.7(35)$ & $\begin{array}{c}15.0(26.3 ; 42.3) \\
P<0.001\end{array}$ \\
\hline
\end{tabular}

$P$-Values are found with the Kruskal-Wallis test. $\mathrm{IQR}$, interquartile range. 
Table 2 Results from multivariable linear regression analyses of male serum reproductive hormones, SHBG and DHEAS among Danish men according to self-reported hours of sleep per day.

\begin{tabular}{|c|c|c|c|c|}
\hline & \multirow[b]{2}{*}{$(n=2095)$} & \multicolumn{3}{|c|}{ Sleep in hours (continuous- and categorized variable) $\boldsymbol{l} \boldsymbol{\beta}(95 \% \mathrm{Cl}), \boldsymbol{P}$ value } \\
\hline & & Model 1* & Model $2 * \star$ & Model $3 * \star *$ \\
\hline \multirow[t]{4}{*}{$\begin{array}{l}\text { Free testosterone } \\
(\mathrm{pmol} / \mathrm{L})\end{array}$} & $\begin{array}{c}\text { Sleep in hours } \\
\text { (continuous) }\end{array}$ & $-6.2(-11.3 ;-1.1) P=0.018$ & $-6.4(-11.3 ;-1.4) P=0.012$ & $-6.4(-11.4 ;-1.4) P=0.012$ \\
\hline & $<7 \mathrm{~h}$ of sleep & $3.3(-7.2 ; 13.8) P=0.538$ & $1.8(8.4 ; 12.1) P=0.728$ & $2.1(-8.2 ; 12.3) P=0.692$ \\
\hline & 7-9 h of sleep & 0 (reference) & 0 (reference) & 0 (reference) \\
\hline & $>9 \mathrm{~h}$ of sleep & $-31.9(-54.3 ;-9.5) P=0.005$ & $-35.6(-57.4 ;-13.8) P=0.001$ & $-35.5(-57.4 ;-13.6) P=0.001$ \\
\hline \multirow{4}{*}{$\begin{array}{l}\text { Bioavailable } \\
\text { testosterone } \\
\text { (nmol/L) }\end{array}$} & $\begin{array}{c}\text { Sleep in hours } \\
\text { (continuous) }\end{array}$ & $-0.2(-0.3 ; 0.0) P=0.023$ & $-0.2(-0.3 ;-0.0) P=0.014$ & $-0.2(-0.8 ;-0.0) P=0.014$ \\
\hline & $<7 \mathrm{~h}$ & $0.1(-0.2 ; 0.3) P=0.685$ & $0.0(-0.3 ; 0.3) P=0.835$ & $0.0(-0.2 ; 0.3) P=0.803$ \\
\hline & $7-9 h$ & 0 (reference) & 0 (reference) & 0 (reference) \\
\hline & $>9 \mathrm{~h}$ & $-0.8(-1.3 ;-0.2) P=0.007$ & $-0.8(-1.4 ;-0.3) P=0.002$ & $-0.8(-1.4 ;-0.3) P=0.003$ \\
\hline \multirow[t]{4}{*}{$\begin{array}{l}\text { Total testosterone } \\
(\mathrm{nmol} / \mathrm{L})\end{array}$} & $\begin{array}{c}\text { Sleep in hours } \\
\text { (continuous) }\end{array}$ & $-0.3(-0.6 ;-0.0) P=0.032$ & $-0.3(-0.6 ;-0.1) P=0.014$ & $-0.3(-0.6 ;-0.1) P=0.020$ \\
\hline & $<7 \mathrm{~h}$ & $0.4(-0.2 ; 1.0) P=0.165$ & $0.3(-0.3 ; 0.9) P=0.285$ & $0.3(-0.3 ; 0.8) P=0.310$ \\
\hline & $7-9 h$ & 0 (reference) & 0 (reference) & 0 (reference) \\
\hline & $>9 \mathrm{~h}$ & $-1.3(-2.5 ; 0.0) P=0.051$ & $-1.5(-2.7 ;-0.3) P=0.012$ & $-1.4(-2.6 ;-0.3) P=0.018$ \\
\hline \multirow[t]{4}{*}{ SHBG (nmol/L) } & $\begin{array}{c}\text { Sleep in hours } \\
\text { (continuous) }\end{array}$ & $-0.4(-1.0 ; 0.3) P=0.291$ & $-0.4(-1.0 ; 0.2) P=0.19$ & $-0.3(-0.9 ; 0.3) P=0.318$ \\
\hline & $<7 \mathrm{~h}$ & $1.3(-0.0 ; 2.6) P=0.053$ & $1.2(-0.0 ; 2.5) P=0.056$ & $1.1(-0.2 ; 2.3) P=0.085$ \\
\hline & $7-9 h$ & 0 (reference) & 0 (reference) & 0 (reference) \\
\hline & $>9 \mathrm{~h}$ & $0.5(-2.3 ; 3.3) P=0.739$ & $0.1(-2.6 ; 2.7) P=0.96$ & $0.4(-2.3 ; 3.1) P=0.776$ \\
\hline \multirow[t]{4}{*}{ DHEAS (nmol/L) } & $\begin{array}{c}\text { Sleep in hours } \\
\text { (continuous) }\end{array}$ & $-0.00(-0.0 ; 0.0) P=0.860$ & $-0.0(-0.0 ; 0.0) P=0.928$ & $-0.0(-0.0 ; 0.0) P=0.657$ \\
\hline & $<7 \mathrm{~h}$ & $-0.03(-0.1 ; 0.1) P=0.463$ & $-0.0(-0.1 ; 0.0) P=0.261$ & $-0.0(-0.1 ; 0.0) P=0.360$ \\
\hline & $7-9 \mathrm{~h}$ & 0 (reference) & 0 (reference) & 0 (reference) \\
\hline & $>9 \mathrm{~h}$ & $-0.06(-0.2 ; 0.1) P=0.443$ & $-0.1(0.3 ; 0.1) P=0.270$ & $-0.1(-0.3 ; 0.0) P=0.146$ \\
\hline
\end{tabular}

*Adjusted for age; **further adjusted for smoking and BMI; ***further adjusted for alcohol intake and physical activity.

DHEAS, dehydroepiandrosterone-sulfate; SHBG, sex hormone-binding globulin.

and cholesterol-lowering medication. Information on asthma, myocardial infarction and diabetes originated from the baseline questionnaire, and information on heart medication and cholesterol-lowering medication originated from the 5-year follow-up.

\section{Outcomes}

Participants were asked to account for their activities during an average day ( $24 \mathrm{~h}$ ) including mean total hours of sleep and rest per night. This sleep variable was divided into >7, 7-9 and >9 $\mathrm{h}$ according to the recommendations of the American National Sleep Foundation (4). From here on and forward this variable will be described as 'total hours of sleep'. The wording of the questionnaire has been published elsewhere (23).

The Inter99 study had the 22 questions from the mental vulnerability questionnaire used for psychometric evaluation (24). We assessed sleep quality by two of these questions 'Do you often feel very tired' and 'Do you often suffer from sleeplessness?' Participants who answered confirmatory to the first and second question were classified as 'often tired' and 'often sleepless', respectively.

\section{Statistics}

SAS, version 9.2 (SAS institute Inc.), was used for all analyses. A complete case analysis was performed and only participants with complete information from blood tests and on all relevant variables of lifestyle factors were included. A $P$ value of $<0.05$ was considered statistically significant.

Descriptive characteristics were presented as percent and total number. Hormones were presented as median and inter quartile range, (IQR), and compared with a nonparametric Kruskal-Wallis test. Total testosterone was presented in Table 1 and free testosterone, bioavailable testosterone, SHBG and DHEAS were presented in Supplementary data.

The distributions of relevant confounders and co-morbidities and men with serum reproductive hormone levels under the diagnostic threshold for hypogonadism, according to classified hours of sleep, were presented
This work is licensed under a Creative Commons Attribution-NonCommercial 4.0 International License. ed from Bioscientifica.com at 04/26/2023 01:16:54PM via free access 
Table 3 The relationship between sleep duration and indicators of quality of sleep.

\begin{tabular}{|c|c|c|c|}
\hline \multirow[b]{2}{*}{$(n=2095)$} & \multicolumn{2}{|c|}{ Often tired $\boldsymbol{n}(\%)$} & \multirow[b]{2}{*}{$P$ value } \\
\hline & Yes & No & \\
\hline$<7 \mathrm{~h}$ of sleep & $82(24.8)$ & 409 (23.2) & \\
\hline 7-9 h of sleep & $213(64.4)$ & 1305 (74.0) & \\
\hline \multirow[t]{4}{*}{ >9 h of sleep } & $36(10.8)$ & $50(2.8)$ & \\
\hline & 331 (100) & $1764(100)$ & $P<0.001$ \\
\hline & \multicolumn{2}{|c|}{ Often sleepless $\boldsymbol{n}(\%)$} & \\
\hline & Yes & No & \\
\hline$<7 \mathrm{~h}$ of sleep & $78(31.5)$ & $413(22.4)$ & \\
\hline 7-9 h of sleep & 151 (60.9) & $1367(74.0)$ & \\
\hline \multirow[t]{2}{*}{ >9 h of sleep } & $19(7.7)$ & 67 (3.6) & \\
\hline & $248(100)$ & $1847(100)$ & $P<0.001$ \\
\hline
\end{tabular}

$P$-Values represent results from chi-square test

as total number, percent and $P$ value according to the chi-square test (Supplementary Table 2).

Multivariable linear regression models were used to calculate $\beta$-coefficients of hormones (95\% confidence interval, CI) according to total hours of sleep as both a categorical (>7, 7-9, and $>9 \mathrm{~h}$ ) and continuous variable. Model 1 was adjusted for age. Model 2 was additionally adjusted for smoking and BMI. Model 3 was additionally adjusted for alcohol intake and physical activity (Table 2).

Chi-square tests were performed to examine the distribution of the two sleep quality indicators across the three classes of total hours of sleep, presented as total number and percent (Table 3).
In additional analyses, a stratified linear regression analyses were performed to present the $\beta$-coefficients (95\% confidence interval, CI) for hormones stratified by total hours of sleep per day ( $>7,7-9$ or $>9 \mathrm{~h}$ ), and whether or not they often felt very tired in their everyday life. The analyses were adjusted for age, smoking, BMI, alcohol intake and physical activity (Table 4).

We performed general additive model (GAM) analyses by modeling the associations between hormones and sleep in additive models in R, package (mcgv). The models were constructed taking age, BMI, smoking, alcohol intake and physical activity into account (Supplementary Fig. 1). The predicted values of our GAM analysis are presented in Supplementary data. SHBG is not included, because of its linearity which is not supported very well in predicted values (Supplementary Fig. 2).

Finally, a multivariable linear regression model (Model 4) was examined, adjusting for co-morbidities in addition to age, smoking, BMI, alcohol intake and physical activity. This is presented as $\beta$-coefficients (95\% confidence interval, CI) for $\mathrm{tT}, \mathrm{fT}, \mathrm{bT}, \mathrm{SHBG}$ and DHEAS, according to sleep as a categorical or a continuous variable (Supplementary Table 3).

The linearity assumption was checked by adding the continuous variables squared and checking for significance. We also tested for a non-linear trend, by dividing continuous variables into quartiles. A non-linear association was found between 'total hours of sleep' and

Table 4 Association between sleep duration and levels of male reproduction hormone stratified by reporting to being often tired or not.

\begin{tabular}{|c|c|c|c|c|}
\hline & \multirow[b]{2}{*}{$(n=2095)$} & \multicolumn{3}{|c|}{ Effect of sleep duration on hormone levels stratified by tiredness/ $\beta(95 \% \mathrm{Cl})$} \\
\hline & & Yes, I am often tired $(n=331)$ & No, I am not often tired $(n=1764)$ & $P$ value for interaction \\
\hline Free testosterone (pmol/L) & $\begin{array}{l}<7 \mathrm{~h} \text { of sleep } \\
7-9 \mathrm{~h} \text { of sleep } \\
>9 \mathrm{~h} \text { of sleep }\end{array}$ & $\begin{array}{c}-28.4(-53.8 ;-3.0) \\
0 \text { (reference) } \\
-48.1(-79.0 ;-17.2)\end{array}$ & $\begin{array}{c}7.7(-3.4 ; 18.9) \\
0 \text { (reference) } \\
-34.9(-63.3 ;-6.6)\end{array}$ & $P=0.037$ \\
\hline $\begin{array}{l}\text { Bioavailable testosterone } \\
\text { (nmol/L) }\end{array}$ & $\begin{array}{l}<7 \mathrm{~h} \text { of sleep } \\
7-9 \mathrm{~h} \text { of sleep } \\
>9 \mathrm{~h} \text { of sleep }\end{array}$ & $\begin{array}{c}-0.7(-1.3 ;-0.1) \\
0 \text { (reference) } \\
-1.1(-1.9 ;-0.2)\end{array}$ & $\begin{array}{c}0.2(-0.1 ; 0.5) \\
0 \text { (reference) } \\
-0.8(-1.5 ;-0.1)\end{array}$ & $P=0.049$ \\
\hline Total testosterone $(\mathrm{nmol} / \mathrm{L})$ & $\begin{array}{l}<7 \mathrm{~h} \text { of sleep } \\
7-9 \mathrm{~h} \text { of sleep } \\
>9 \mathrm{~h} \text { of sleep }\end{array}$ & $\begin{array}{c}-1.8(-3.2 ;-0.5) \\
0 \text { (reference) } \\
-3.0(-4.9 ;-1.1)\end{array}$ & $\begin{array}{c}0.7(0.1 ; 1.3) \\
0 \text { (reference) } \\
-0.7(-2.3 ; 0.8)\end{array}$ & $P=0.004$ \\
\hline SHBG (nmol/L) & $\begin{array}{l}<7 \mathrm{~h} \text { of sleep } \\
7-9 \mathrm{~h} \text { of sleep } \\
>9 \mathrm{~h} \text { of sleep }\end{array}$ & $\begin{aligned}-2.8 & (-5.9 ; 0.2) \\
0 & (\text { reference }) \\
-5.6 & (-9.9 ;-1.3)\end{aligned}$ & $\begin{array}{c}1.8(0.5 ; 3.2) \\
0 \text { (reference) } \\
3.9(0.4 ; 7.3)\end{array}$ & $P<0.001$ \\
\hline DHEAS (nmol/L) & $\begin{array}{l}<7 \mathrm{~h} \text { of sleep } \\
7-9 \mathrm{~h} \text { of sleep } \\
>9 \mathrm{~h} \text { of sleep }\end{array}$ & $\begin{aligned}-0.2 & (-0.4 ; 0.0) \\
0 & (\text { reference }) \\
-0.0 & (-0.3 ; 0.2)\end{aligned}$ & $\begin{aligned} &-0.0(-0.4 ; 0.1) \\
& 0 \text { (reference) } \\
&-0.2(-0.4 ; 0.0)\end{aligned}$ & $P=0.143$ \\
\hline
\end{tabular}

Results from multivariable linear regression analyses of male serum reproductive hormones, SHBG and DHEAS among Danish men according to self-reported hours of sleep per day and whether or not they often feel very tired in their everyday life. Adjusted for age, smoking, BMI, alcohol intake and physical activity.

DHEAS, dehydroepiandrosterone-sulfate; SHBG, sex hormone-binding globulin.

https://ec.bioscientifica.com

https://doi.org/10.1530/EC-18-0548 (c) 2019 The authors Published by Bioscientifica Ltd

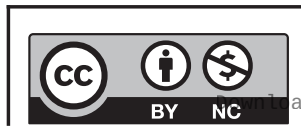

This work is licensed under a Creative Commons Attribution-NonCommercial 4.0 International License. ded from Bioscientifica.com at 04/26/2023 01:16:54PM 
$\mathrm{tT}$, $\mathrm{fT}$ and $\mathrm{bT}$. This provided the basis for dividing the sleep variable into $>7,7-9$ and $>9 \mathrm{~h}$ as recommended by the American National Sleep Foundation (4). The interactions between self-reported total hours of sleep and both sleep quality variables 'often very tired' and 'often sleepless' were tested on hormones (Table 4). We examined the validity of the linear regression models by checking leverage, residual plots and Cook's distance.

\section{Results}

Table 1 describes the characteristics of the 2095 men participating in the study. None of the two indicators of quality of sleep were significantly associated with any of the outcomes. Total hours of sleep showed statistically significant $(P<0.05)$ associations with $\mathrm{tT}, \mathrm{fT}, \mathrm{bT}$ and DHEAS, but not with SHBG. High age, high BMI, no smoking and low levels of physical activity showed statistically significant $(P \leq 0.05)$ associations with lower tT, fT, bT, SHBG and DHEAS. Alcohol intake was only significantly associated with SHBG $(P \leq 0.05)$. The relationship between potential confounders and sleep duration (self-reported total hours of sleep per day) is shown in Supplementary Table 2. One hundred thirtythree participants were excluded from the analyses due to incomplete information on co-morbidities. In the adjusted model 3 with sleep as a continuous variable (Table 2), we found inverse associations of sleep with concentrations of fT $(\beta=-6.495 \%$ CI: $-11.4 ;-1.4)$, bT $(\beta=-0.2 ; 95 \%$ CI: $-0.3 ;-0.0)$ and tT $(\beta=-0.3$; 95\% CI: $-0.5 ;-0.1)$. However, we observed a nonlinear pattern when sleep was used as a categorical variable, that is, men who slept more than $9 \mathrm{~h}$, had lower concentrations of fT $(\beta=-35.5 ; 95 \% \mathrm{CI}:-57.5$; $-13.6)$, bT ( $\beta=-0.8 ; 95 \%$ CI: $-1.4 ;-0.3)$ and $\mathrm{tT}(\beta=-1.4$; $95 \%$ CI: $-2.6 ;-0.3)$ compared to $7-9 \mathrm{~h}$, while no statistically significant differences in testosterone concentrations were observed between men sleeping less than $7 \mathrm{~h}$ vs 7-9 h. In the adjusted model 3 there was no statistically significant association of total hours of sleep with SHBG and DHEAS.

Regarding the relationship between total hours of sleep and quality of sleep (Table 3), $7.7 \%$ of the men who were 'often sleepless' slept more than $9 \mathrm{~h}$ compared to $3.6 \%$ of the men not who were not. A total of $10.8 \%$ of the men who were 'often very tired' slept more than $9 \mathrm{~h}$ compared to $2.8 \%$ of the men who were not 'often very tired'. Thus, the group that slept more than $9 \mathrm{~h}$ more often reported tiredness and sleeplessness.
We observed a statistically significant interaction between being 'often tired' and sleep duration with regard to effects on levels of male reproductive hormone and therefore we also present analyses stratified by reporting to be 'often tired' (Table 4). Among participants experiencing being 'often tired', sleeping more than $9 \mathrm{~h}$ was more strongly associated with reduced levels of $\mathrm{tT}$, fT, bT and SHBG, but not DHEAS, after multivariable adjustment; and sleeping less than $7 \mathrm{~h}$ was significantly associated with reduced levels of $\mathrm{tT}$, fT and bT.

In supplemental analyses we performed GAM analyses based on hormones as continuous variables (Supplementary Fig. 1). The results showed a borderline statistical significant relationship for the association between free testosterone and sleep in hours, but no other statistical significant associations were found.

Self-reported myocardial infarction, diabetes, asthma, heart medication and cholesterol-lowering medicine were significantly associated with sleeping more than $9 \mathrm{~h}$ (Supplementary Table 2), but sensitivity analyses with additional adjustment for comorbidity did not substantially change the revealed estimates (Supplementary Table 3).

\section{Discussion}

In a population-based study of 2095 men, we found no association between self-reported sleep quality and serum levels of male reproductive hormones. We found a statistically significant association from continuous analysis of 'sleep in hours' and hormones. We hypothesized of an inverted u-shaped association between sleep and male hormones and examined this in our categorized analysis. We did not observe any differences in levels of hormones between men sleeping less than $7 \mathrm{~h}$ compared to men sleeping 7-9h. Of note, however, men sleeping more than $9 \mathrm{~h}$ had lower mean serum levels of fT, bT and tT compared to the men sleeping 7-9 h. We found no inverted $\mathrm{u}$-shape but confirmed the association we found in our linear analysis. This association was further examined in our GAM analysis, where no statistically significant associations were found.

The observed lack of associations between sleep quality and serum levels of hormones is consistent with three other cross-sectional studies $(14,15,16)$. However, one study found an association between a reduction in testosterone concentrations and less healthy sleep defined both as sleep efficiency and wake time after sleep onset (WASO) in 1312 older men (13). 
We did not observe any difference in levels of hormones between men sleeping less than $7 \mathrm{~h}$ compared to $7-9 \mathrm{~h}$ in our multivariable analyses, but found an association when stratifying our analyses by reporting to being often tired or not. This is somewhat inconsistent with two previous studies: One study in 531 healthy Singaporean men found that men who sleep less than $6 \mathrm{~h}$ had significantly lower testosterone levels (17) and another smaller study, with 66 male medical students, replicated these results (18). The observed lack of association in our study could be explained by our classification in three groups of men sleeping less than 7, 7-9 and more than $9 \mathrm{~h}$. There could be a threshold with a rather steep drop, right around the 6-7 h mark of sleep duration; however, a study in 796 Chinese men who were classified into half-hour classes of sleep, also did not find such an association (19). We know however from the physiology that testosterone is restored to its peak after approximately 90 min of sleep, even though we are unable to examine such restricted sleep in our data. Our observations from the stratified analyses could support that the need for sleep differs between individuals. Thus, our results indicated that in men, who do not report being tired, sleeping less than $7 \mathrm{~h}$ is not associated with reduced concentrations of testosterone, while in contrast, men who report being tired, sleeping less than $7 \mathrm{~h}$ is associated with reduced serum testosterone.

Even though these results are significant, they are a result of multiple testing and would be non-significant under a Bonferroni correction of our $P$ value.

Our results made us hypothesize that there may be an inverted u-shaped association between sleep duration and testosterone concentrations. In comparison, two studies found an inverted u-shaped association between sperm quality and sleep quality (14) or sleep duration (19), but both of them examined male serum reproductive hormones, without observing a similar u-shaped pattern. Other studies have examined excessive sleeping and male serum reproductive hormones, but none of them found a similar association to our study. Methodical differences could possibly explain the inconsistent results. Two studies did not classify sleep, and chose a linear regression analysis instead, and did not find any association (13, 15). Two studies did classify sleep, but their group of men sleeping the most was men sleeping more than $8 \mathrm{~h}$ and we hypothesize that the threshold for a reduction in testosterone concentrations may be observed in men sleeping more than $9 \mathrm{~h}$. These studies did not find any association between men sleeping more than $8 \mathrm{~h}$ and serum levels of testosterone $(17,18)$. One study in 769 males, did compare levels of serum testosterone between men sleeping more and less than $9 \mathrm{~h}$, but could not detect significant associations (19).

The association between restricted sleep and a reduction in serum testosterone have in previous studies been explained by the direct effect of sleep on the synthesis and release of $\operatorname{GnRH}(3,12)$, but the inverted $\mathrm{u}$-shape between sleep duration and testosterone is more difficult to explain. Interestingly, a similar u-shaped association between sleep duration and mortality has been found and studied quite thoroughly $(9,10,11)$, although the possible biological mechanisms underlying this association are not clarified. It is possible that the pathogenesis is mediated by obesity but adjusting for BMI in our study did not change the results. Alternatively, cancer-fatigue also seems likely to influence both sleep and testosterone, and depression is also a possible explanation, but one study excluded participants who self-reported suffering from depression and thereby surprisingly strengthened the $u$-shaped association between sleep duration and sperm quality. However, they found no association with male serum reproductive hormones (14). Self-reported sleep time is known to be underreported among insomniacs. Insomnia is frequently co-morbid with depression and other studies have found a strong correlation between excessive sleeping and depression (9). There is also a known association between low testosterone and depression, and it is a possibility that we are observing the effect of depression on both testosterone and insomnia, with no causality between the outcomes. In addition, a chronic state of stress, could also lead to excessive sleep, and an increase in levels of cortisol. It could be speculated that an increase in cortisol synthesis would skew the distribution of cholesterol away from the testosterone synthesis, since they share part of the same pathway and the same intermediate product of $17 \alpha$-hydroxy-progesterone. Further studies are needed to examine the physiological effect of excessive sleep on the body's homeostasis.

We hypothesized that higher prevalence of chronic diseases in men sleeping more than $9 \mathrm{~h}$ could at least partly explain why these men had lower hormone levels in our study. We did confirm a higher prevalence of co-morbidities in men sleeping $>9 \mathrm{~h}$ lending support to that idea. However, when adjusting for co-morbidities in multivariable models the associations between long sleep duration and low hormone levels remained. This does not rule out residual confounding by co-morbidities, which is supported by the fact that many potential confounders were found to be significantly associated with sleep duration (Supplementary Table 2). 
Finally, we investigated the association between excessive sleep and testosterone further in our GAM analysis and found a borderline statistically significant relationship for the association between free testosterone and sleep in hours, but no other statistically significant association were found. Overall across our different analysis, we have found no clear association between excessive sleep and testosterone.

The current study has several limitations. First, in the present cross-sectional study, we cannot determine the causal direction of the effect. Thus, we cannot determine whether low hormone levels causes increased need for sleep or the increased sleep causes low hormone levels. This would be better examined in a longitudinal study. Secondly, the sleep quality variable was assessed by two questions - 'Do you often feel very tired' and 'Do you often suffer from sleeplessness?'. These questions most likely cover only some aspects of possible diminished sleep quality and may have been more accurately measured by using more established indexes such as the 'Munich Chronotype Questionnaire', the 'Epworth Sleepiness Scale', or the 'Pittsburg Sleep Quality Index'. Thirdly, the lack of depressive symptoms or measures of diagnosed depression, limits the studies' ability to differentiate between what could be an association between sleep and testosterone and what could be two outcomes of depression. Hence, the results should be confirmed by longitudinal studies and maybe even experimental studies, although increasing sleep duration beyond $9 \mathrm{~h}$ may be difficult.

\section{Conclusion}

In conclusion, we found no association between serum levels of male reproductive hormones and sleep quality or restrictive sleep. We did find an association between excessive sleep and reduced concentrations of testosterone in our linear and categorized analyses, but this association was found to be statistically non-significant in our generalized additive model. To our knowledge, this association has not been found in previous studies. Further studies are needed to decipher the direction of association between excessive sleep and low testosterone based on prospective samples.

\section{Supplementary data}

This is linked to the online version of the paper at https://doi.org/10.1530/ EC-18-0548.

\section{Declaration of interest}

Anna-Maria is a Senior Editor for Endocrine Connections. She was not involved in the review or editorial process for this paper, on which she is listed as an author. The other authors have nothing to declare.

\section{Funding}

This research did not receive any specific grant from any funding agency in the public, commercial or not-for-profit sector.

\section{Acknowledgments}

The authors would like to thank the participants and all members of the Inter99 staff at Research Centre for Prevention and Health. The Inter99 study was initiated by Torben Jørgensen, DMSci (principal investigator); Knut Borch-Johnsen, DMSci, (co-principal investigator); Troels Thomsen, PhD; and Hans Ibsen, DMSci. The Steering Committee comprises Torben Jørgensen and Charlotta Pisinger, PhD, MPH.

\section{References}

1 Wu FCW, Tajar A, Beynon JM, Pye SR, Silman AJ, Finn JD, O'Neill TW, Bartfai G, Casanueva FF, Forti G, et al. Identification of late-onset hypogonadism in middle-aged and elderly men. New England Journal of Medicine 2010363 123-135. (https://doi. org/10.1056/NEJMoa0911101)

2 Dandona P \& Rosenberg MT. A practical guide to male hypogonadism in the primary care setting. International Journal of Clinical Practice 201064 682-696. (https://doi.org/10.1111/j.17421241.2010.02355.x)

3 Andersen ML \& Tufik S. The effects of testosterone on sleep and sleep-disordered breathing in men: its bidirectional interaction with erectile function. Sleep Medicine Reviews 200812 365-379. (https:// doi.org/10.1016/j.smrv.2007.12.003)

4 Ohayon M, Wickwire EM, Hirshkowitz M, Albert SM, Avidan A, Daly FJ, Dauvilliers Y, Ferri R, Fung C, Gozal D, et al. National Sleep Foundation's sleep quality recommendations: first report. Sleep Health 20173 6-19. (https://doi.org/10.1016/j.sleh.2016.11.006)

5 Roth T \& Roehrs T. Insomnia: epidemiology, characteristics, and consequences. Clinical Cornerstone 20035 5-15. (https://doi. org/10.1016/S1098-3597(03)90031-7)

6 Roth T. Insomnia: definition, prevalence, etiology, and consequences. Journal of Clinical Sleep Medicine 20073 (5 Supplement) S7-S10.

7 Grandner MA. Sleep, health, and society. Sleep Medicine Clinics 2017 12 1-22. (https://doi.org/10.1016/j.jsmc.2016.10.012)

8 Dauvilliers Y \& Buguet A. Hypersomnia. Dialogues in Clinical Neuroscience 20057 347-356.

9 Patel SR, Malhotra A, Gottlieb DJ, White DP \& Hu FB. Correlates of long sleep duration. Sleep 200629 881-889. (https://doi.org/10.1093/ sleep/29.7.881)

10 Cappuccio FP, D’Elia L, Strazzullo P \& Miller MA. Sleep duration and all-cause mortality: a systematic review and meta-analysis of prospective studies. Sleep 201033 585-592. (https://doi.org/10.1093/ sleep/33.5.585)

11 Liu Y, Wheaton AG, Chapman DP \& Croft JB. Sleep duration and chronic diseases among U.S. adults age 45 years and older: evidence from the 2010 Behavioral Risk Factor Surveillance System. Sleep 2013 36 1421-1427. (https://doi.org/10.5665/sleep.3028)

12 Wittert G. The relationship between sleep disorders and testosterone. Current Opinion in Endocrinology, Diabetes, and Obesity 201421 239-243. (https://doi.org/10.1097/MED.0000000000000069)

13 Barrett-Connor E, Dam TT, Stone K, Harrison SL, Redline S, Orwoll E $\&$ Osteoporotic Fractures in Men Study Group. The association of

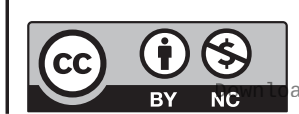

This work is licensed under a Creative Commons Attribution-NonCommercial 4.0 International License. Atribution 
testosterone levels with overall sleep quality, sleep architecture, and sleep-disordered breathing. Journal of Clinical Endocrinology and Metabolism 200893 2602-2609. (https://doi.org/10.1210/jc.20072622)

14 Jensen TK, Andersson A-M, Skakkebaek NE, Joensen UN, Blomberg Jensen MB, Lassen TH, Nordkap L, Olesen IA, Hansen AM, Rod NH, et al. Association of sleep disturbances with reduced semen quality: a cross-sectional study among 953 healthy young Danish men. American Journal of Epidemiology 2013177 1027-1037. (https://doi. org/10.1093/aje/kws420)

15 Kische H, Ewert R, Fietze I, Gross S, Wallaschofski H, Volzke H, Dorr M, Nauck M, Obst A, Stubbe B, et al. Sex hormones and sleep in men and women from the general population: a cross-sectional observational study. Journal of Clinical Endocrinology and Metabolism 2016101 3968-3977. (https://doi.org/10.1210/jc.2016-1832)

16 Ponholzer A, Plas E, Schatzl G, Struhal G, Brossner C, Mock K, Rauchenwald M \& Madersbacher S. Relationship between testosterone serum levels and lifestyle in aging men. Aging Male 2005 8 190-193. (https://doi.org/10.1080/13685530500298154)

17 Goh VH, Tong TY, Mok HP \& Said B. Interactions among age, adiposity, bodyweight, lifestyle factors and sex steroid hormones in healthy Singaporean Chinese men. Asian Journal of Andrology 20079 611-621. (https://doi.org/10.1111/j.1745-7262.2007.00322.x)

18 Khan M, Ahmed A \& Ku A. Effect of endogenous sex steroids on sleep habits in male medical students. Journal of Rawalpindi Medical College 20152015 89-92.
19 Chen Q, Yang H, Zhou N, Sun L, Bao H, Tan L, Chen H, Ling X, Zhang G, Huang L, et al. Inverse U-shaped association between sleep duration and semen quality: longitudinal observational study (MARHCS) in Chongqing, China. Sleep 201639 79-86. (https://doi. org/10.5665/sleep.5322)

20 Jorgensen T, Borch-Johnsen K, Thomsen TF, Ibsen H, Glumer C \& Pisinger C. A randomized non-pharmacological intervention study for prevention of ischaemic heart disease: baseline results Inter99. European Journal of Cardiovascular Prevention and Rehabilitation 2003 10 377-386. (https://doi.org/10.1097/01.hjr.0000096541.30533.82)

21 Vermeulen A, Verdonck L \& Kaufman JM. A critical evaluation of simple methods for the estimation of free testosterone in serum. Journal of Clinical Endocrinology and Metabolism 199984 3666-3672. (https://doi.org/10.1210/jcem.84.10.6079)

22 Obesity: preventing and managing the global epidemic. Report of a WHO consultation. World Health Organization Technical Report Series 2000894 i-xii, 1-253.

23 Andersen LG, Groenvold M, Jorgensen T \& Aadahl M. Construct validity of a revised physical activity scale and testing by cognitive interviewing. Scandinavian Journal of Public Health 201038 707-714 (https://doi.org/10.1177/1403494810380099)

24 Eplov LF, Petersen J, Jorgensen T, Johansen C, Birket-Smith M, Lyngberg AC \& Mortensen EL. The mental vulnerability questionnaire: a psychometric evaluation. Scandinavian Journal of Psychology 201051 548-554. (https://doi.org/10.1111/j.14679450.2010.00834.x)

Received in final form 27 December 2018

Accepted 22 January 2019

Accepted Preprint published online 22 January 2019
This work is licensed under a Creative Commons Attribution-NonCommercial 4.0 International License. ded from Bioscientifica.com at 04/26/2023 01:16:54PM 